\title{
Multimodal Anti-tumor Approaches Combined with Immunotherapy to Overcome Tumor Resistance in Esophageal and Gastric Cancer
}

\author{
LOUISA BOLM ${ }^{1}$, LUKAS KÄSMANN ${ }^{2}$, ANNIKA PAYSEN ${ }^{1}$, CHRIS KARAPETIS $^{3}$, \\ DIRK RADES ${ }^{2}$, ULRICH F. WELLNER ${ }^{1}$, TOBIAS KECK ${ }^{1}$, \\ DAVID I. WATSON ${ }^{3,4}$, RICHARD HUMMEL ${ }^{1}$ and DAMIAN J. HUSSEY ${ }^{3,4}$ \\ ${ }^{1}$ Department of Surgery, UKSH Campus Luebeck, University of Luebeck, Luebeck, Germany; \\ ${ }^{2}$ Department of Radiation Oncology, UKSH Campus Luebeck, University of Luebeck, Luebeck, Germany; \\ ${ }^{3}$ Flinders Centre for Innovation in Cancer, College of Medicine and Public Health, \\ Flinders University, Bedford Park, Australia; \\ ${ }^{4}$ Discipline of Surgery, College of Medicine and Public Health, Flinders University, Bedford Park, Australia
}

\begin{abstract}
Upper gastrointestinal malignancies are associated with a high disease burden worldwide, and esophageal and gastric cancers represent the most common entities. Given a lack of early characteristic symptoms and potent screening instruments, the majority of patients present with advanced disease at the time of diagnosis. Complete surgical resection is a first-line curative option, and multimodal approaches involving chemotherapy and radiotherapy further improve patient prognosis. However, response to standard adjuvant and neoadjuvant treatments remains low, and new strategies are warranted to increase tumor control rates. Immunotherapy is emerging in various cancer entities and may be successfully combined with standard therapeutic regimens to improve patient outcome. For the purpose of this review we aimed to assess combined approaches of immunotherapy and standard treatment options such as chemotherapy, radiotherapy and surgery. Current trials evaluating multimodal approaches with immunotherapy in esophageal and gastric cancer are evaluated.
\end{abstract}

This article is freely accessible online.

Correspondence to: Damian J. Hussey, Discipline of Surgery, College of Medicine and Public Health, Flinders University South Australia, Bedford Park, SA 5042, Australia. Tel: +618 82046091, Fax: +618 82046130, e-mail: damian.hussey@flinders.edu.au

Key Words: Immunotherapy, esophageal cancer, gastric cancer, multimodal therapy, review.
Esophageal and gastric cancer are aggressive solid carcinomas, and represent the most prevalent cancer entities of the upper gastrointestinal tract (1). Complete surgical resection remains the primary curative option in these tumors. However, 5-year overall survival is limited in patients undergoing surgery alone (2-4). Multimodal regimens involving chemotherapy and radiotherapy in addition to surgical resection improve disease control. As the majority of patients present with locally advanced tumors unresectable at time of diagnosis, neoadjuvant therapies are increasingly studied (5-7). The use of multi-agent chemotherapeutic protocols such as FOLFOX (fluorouracil, folinic acid, oxaliplatin), capecitabine and oxaliplatin, carboplatin and paclitaxel combined with radiotherapy, or cisplatin and fluorouracil with or without radiotherapy, has been successfully introduced to improve disease control in upper gastrointestinal malignancies $(5,8,9)$. In the treatment of adenocarcinoma of the stomach and gastro-oesophageal junction, the FLOT protocol (docetaxel, oxaliplatin, fluorouracil, leucovorin) was established as standard neoadjuvant option, and is currently being investigated in further phase III trials (10-12). Despite the development of multimodal approaches, prognosis in esophageal and gastric cancer remains poor and novel strategies to improve resection rates, tumor control and overall survival are needed.

Immunotherapy approaches which reprogram the immune response in order to target tumor cells, have broadened the scope of anti-cancer therapy. In non-small cell lung cancer (NSCLC) and melanoma, immuno-checkpoint inhibitors have markedly improved patient prognosis and have led to a major change in clinical practice guidelines (13-19). In gastrointestinal malignancies, tumor-targeted immuno-response has been identified as relevant prognostic parameter and potential 
therapeutic target $(20,21)$. Several studies show promising results of immunotherapy in upper gastrointestinal malignancies $(22,23)$. The combination of immunotherapy with standard chemo- and radiotherapy may enhance the efficacy of multimodal therapy. At the current stage of development it has become apparent that research efforts should be directed towards determining optimal timing, doses and methods of delivery for such multimodal approaches (24). With further research, it is possible that development of tailored combined approaches could overcome tumor resistance in some patients with upper gastrointestinal malignancies. The aim of this article was to review the current results of multimodal regimens combining immunotherapy and chemo- or radiotherapy in esophageal and gastric cancer. We begin with a description of the major modes of immunotherapy and summaries of their application in upper gastrointestinal cancers, and then explore their combination with standard therapies in specific sections on each major subtype of upper gastrointestinal tumor.

\section{Immunotherapy Concepts in Upper Gastrointestinal Malignancies}

Passive targeted antibody-based immunotherapy. Biological therapy is emerging in several cancer entities, and targeted antibody-based therapies are the most studied option to date (25). Targeted antibodies act against specific tumor features or tumor-promoting mechanisms. Antibody-based therapy has revolutionized the standard of antitumor therapy in melanoma and lung cancer (26-28). The efficacy of antibody-based therapy was also shown for multiple other cancer entities such as renal cancer, bladder cancer and head and neck cancer (25).

In the field of upper gastrointestinal malignancies, a broad variety of targets for antibody-based therapies were identified $(29,30)$. A selection of effective or promising options will be discussed in the context of this overview.

Human epidermal growth factor receptor 2 (HER-2), a protooncogene, was initially identified as an overexpressed tyrosine kinase and negative prognostic factor in one third of breast cancer patients (31). Overexpression of HER-2 was also found in esophageal and gastric cancer patients resulting in poor prognosis $(32,33)$. Trastuzumab, a HER-2-targeted monoclonal antibody was evaluated in clinical trials of HER2 positive gastric cancer, and proved efficacy in terms of safety, tumor regression and improved overall survival rates (34). Other HER-2 targeted agents such as lapatinib, a combined inhibitor of HER-2 and epidermal growth factor (EGFR) showed only minor improvements in response rates in locally advanced esophageal and gastric cancer (35). Pertuzumab, which targets a different epitope of HER-2 than trastuzumab, has been used in combination with trastuzumab in breast cancer patients and provided significantly better outcomes than either antibody alone (36). The combination of Pertuzumab and trastuzumab has also shown increased efficiency in a xenograft model of HER-2 positive human gastric cancer (37). In the phase II/III GATSBY trial, HER-2 positive advanced gastric cancer patients received trastuzumab emtansine versus taxane as second-line therapy (38). In this trial, trastuzumab emtansine failed to show superiority in terms of overall survival. The combination of pertuzumab, Trastuzumab and chemotherapy is currently evaluated as a first-line option in HER-2 metastatic gastric or gastroesophageal junction cancer in the phase III JACOB trial.

Vascular endothelial growth factor receptor (VEGFR) as a determinant of cancer-associated neo-angiogenesis qualifies as an attractive anticancer target. The VEGFR-inhibitor bevacizumab is an established effective therapy in several cancers including colorectal cancer, ovarian cancer and nonsmall cell lung cancer - but only in the context of advanced stage or metastatic tumors and not as an adjuvant therapy (39). Angiogenetic factors may impact prognosis, and for instance hepatocyte growth factor and follistatin expression were associated with reduced overall survival in esophageal cancer patients (40). Another study identified angiopoetin-2 and follistatin as prognostic biomarkers in gastric cancer patients, and the angiopoetin/VEGFR ratio and leptin expression were associated with clinical treatment response (41). Anti-VEGFRagents have been trialed in patients with upper gastrointestinal malignancies. Bevacizumab in addition to chemotherapy was associated with improved progression-free survival and overall response rates in locally advanced gastric cancer, however, overall survival was not impacted (42). Ramucirumab, a monoclonal VEGFR-2 antagonist, even prolonged overall survival (5.2 months versus 3.8 months) in advanced gastric cancer patients having progressed after first-line treatment as shown in the phase III REGARD trial (43).

Immunocheckpoint inhibitors have gained increasing focus in current clinical trials. Interaction of tumor cells via PD-L1 (programmed death ligand 1) severely blocks T-cell antitumor cytotoxic effects (44). Targeting PD-L1 effectively decreases tumor-associated immunosuppression. Anti-PD-L1 therapy with nivolumab or pembrolizumab is highly effective in several cancer entities such as melanoma and non-small cell lung cancer $(45,46)$. In gastric cancer PD-L1 overexpression was recently identified as a negative prognostic parameter (47). PD-L1 expression was detected in $25-65 \%$ of gastric cancer patients and was associated with local invasion, tumor progression and lymph node metastasis $(48,49)$. Trials on PD-1-targeted agents will be discussed below for esophageal cancer and gastric cancer respectively.

Cytokine-induced killer cells and adoptive immunotherapy. Adoptive immunotherapy involves the use of tumor-specific cytotoxic T-cells in order to establish tumor immunity via specific anti-tumor T-cell activity. Tumor-infiltrating lymphocytes are expanded ex vivo and administered to patients to home to the tumor. In this context, the proliferation 
of tumor-infiltrating lymphocytes is often boosted by interleukin 2 (IL-2), a potent T-cell growth factor $(50,51)$. Rosenberg et al. conducted the first study administering lymphokine-activated killer cells and IL-2 in patients with metastatic cancer (52). The treatment was well-tolerated and tumor regression was achieved in a minority of the study population. In a subsequent study of metastatic melanoma patients, a modified protocol for ex vivo culture of tumorinfiltrating lymphocytes was used. Following administration of cultured lymphocytes with high dose IL-2 $50 \%$ of the studied patient population showed tumor response (53).

Adoptive immunotherapy trials for upper gastrointestinal malignancies have focused on tumor-infiltrating T-cells acting against tumor-entity-specific antigens. In esophageal and gastric cancer, adoptive immunotherapeutic strategies involving cytokine-induced killer cells show promising results. Cytokine-induced killer cells are T-cells exposed to various cytokines such as $\mathrm{CD}^{+}$ex vivo. These cells distinctly limit tumor growth and booster cytotoxic response $(54,55)$.

Although studies demonstrate adoptive immunotherapy to specifically induce tumor response, and first clinical studies show promising results, resistance to adoptive immunotherapy is still an obstacle. Two recent studies have made significant progress in this area. A CRISPR-Cas9 gene editing study has identified several expected and novel gene and microRNA candidates which are associated with resistance across several cancer types (56), and development of drugs targeting these may have future clinical potential. Administration of a soluble inhibitor of Fas/Fas-ligand interaction, in the TiRP preclinical model mouse model of melanoma, resulted in substantially decreased apoptosis of tumor infiltrating lymphocytes (57). Thus, interfering with Fas signaling may represent a clinically viable mechanism for overcoming immunotherapy resistance.

Dendritic cell-based vaccination therapy. Vaccination approaches in anticancer therapy aim to induce cancerspecific immunity by presenting tumor-associated peptide antigens to T-cells $(21,58)$. Dendritic cells (DC) are competent to process and present antigens via major histocompatibility complex molecules. Consequently, DC regulate T-cell immunity by recruiting naive and memory T-cells, and qualify as mediators of tumor vaccination therapy (59). Immature DC show a higher phagocytic antigen uptake, while mature DC mainly activate T-cell response and the production of co-stimulatory molecules. For therapeutic purpose, monocytes are cultured to generate immature DC, and subsequently co-cultivated with maturation stimulating cytokines ex vivo $(60,61)$. These DC are administered to patients thereby activating T-cells to migrate to the site of antigen expression and inducing cytotoxic T-cell activity.

In upper gastrointestinal malignancies, various strategies for DC-based vaccination therapy have been studied (60). Transfer of antigen peptide-bearing mature DC resulted in antigen-specific T-cell response, and was well-tolerated in patients with gastric cancer $(62,63)$. In a study by Tanaka et al., patients with gastrointestinal malignancies received mature DC pulsed with MAGE3 peptides which are selectively expressed in gastrointestinal tumor tissue (64). This resulted in peptide-specific T-cell responses, tumor marker decrease and minor tumor regressions in several patients.

The effects of DC-based vaccination therapy may be limited by cells of the tumor microenvironment such as regulatory T-cells, myeloid-derived suppressor cells or tumor-associated macrophages $(65,66)$. These cells mutually generate an anti-inflammatory environment by secreting immunosuppressive substances. This is a major obstacle, and several attempts have been made to overcome tumorassociated immuno-tolerance. Initial studies in gastrointestinal malignancies have applied pulsed DC together with tumor-antigen loaded nanoparticles, resulting in slow and sustained release of antigens $(67,68)$. Another potential option to enhance therapeutic effects of DC-based vaccination may be a combination with standard treatment options like chemotherapy and radiotherapy.

\section{Esophageal Cancer}

Esophageal cancer is the eighth most common cancer worldwide associated with poor prognosis and great variation in incidence, mortality and histopathology based on geographic regions (69-71). Five-year survival rates of all patients depend on stage, genetics and health care quality and range from 15$25 \%$ (69). The two most common subtypes of esophageal cancer are esophageal squamous cell cancer (ESCC) and esophageal adenocarcinoma (EAC) representing over $95 \%$ of all histologic types. ESCC is a particularly high burden in the region of East Asia and Eastern/Southern Africa (70).

Surgery is the standard-of-care option for localized esophageal cancer. Patients presenting with locally advanced stages benefit from neoadjuvant treatment including chemotherapy alone or radio-chemotherapy as to achieve tumor regression and improve resectability rates (72). A benefit in terms of overall survival was only observed in patients showing major histopathologic response (regression to less than $10 \%$ of the primary tumor) to neoadjuvant therapy. However, major histopathological response rates to current neoadjuvant strategies remain as low as $40-50 \%$ (73).

Mechanisms of therapeutic failure in esophageal cancer involve cell cycle checkpoint regulation, cancer stem cells, components of the tumor-associated microenvironment and regulatory $\mathrm{T}$ cells $(74,75)$.

Checkpoint inhibitors are frequently expressed in esophageal cancer and identified as potential targets of antibody therapy (76). Inhibition of PD-1 has been investigated in several types of cancer $(77,78)$. Antitumor 
response is enhanced via inactivation of PD-1 suppressing antitumor T-cell activation. In a study by Kudo et al., nivolumab treatment was evaluated in refractory esophageal cancer (79). Overall, 65 patients were enrolled, and the authors showed promising results and adequate tolerance for nivolumab (79). Pembrolizumab, PD-1-targeted antibody, has been evaluated in the phase Ib KEYNOTE-028 trial as at least third line treatment in PD-L1 positive advanced esophageal cancer (80). $74 \%$ of 23 patients in the esophageal cohort had squamous cell histology. Distinct subgroup analyses of squamous cell and adenocarcinoma are not available yet, however, an analysis of respective effects of PD-L1 targeted therapy in both histological subtypes would be of interest. Objective response rate was $30 \%$, and $13 \%$ of the patients had stable disease. Progression-free survival at 6 months was $30 \%$, and $22 \%$ at 12 months. Final results are not available yet.

Regarding antibody based therapies, treatment with trastuzumab has been established for gastric cancer, however the prognostic role of HER-2 expression in esophageal cancer is unclear (81). In a phase I/II trial by Safran et al., trastuzumab was combined with neoadjuvant radiochemotherapy followed by surgery in 19 patients with locally advanced HER-2-positive esophageal cancer (82). Additional trastuzumab was well-tolerated. Bang et al. randomized 594 patients to chemotherapy alone or chemotherapy in combination with trastuzumab in advanced gastroesophageal or gastric cancer (34). Patients receiving combined immunotherapy were more likely to respond to treatment and lived about 2.4 months longer as compared to patients receiving chemotherapy alone.

Not only passive antibody-based immunotherapy, but also active immunotherapy is on the rise in esophageal cancer. Dendritic cells are one of the most potent antigen-presenting cells capable of ingesting apoptotic tumor cells and presenting tumor-associated antigens to T-cells (83). In pre-clinical studies, DC-based strategies showed strong effects against esophageal carcinoma cell lines (84), and were evaluated in clinical phase I/II studies to assess feasibility and efficacy (85).

First studies combine DC-based immunotherapy with standard treatment options to enhance therapeutic effects in esophageal cancer. In a study by Yan et al., 68 elderly patients were randomized to receive definitive intensitymodulated radiotherapy alone versus intensity-modulated radiotherapy combined with DC-based immunotherapy with cytokine-induced killer cells for mainly locally advanced esophageal cancer. The authors reported an improvement in quality of life, immune function, as well as a decrease in bone marrow suppression, and a prolongation of overall survival time in patients receiving additional DC-based immunotherapy (86). DC-based immunotherapy was associated with insomnia, but no other specific side-effects were observed. Median time to progression was 13.6 months in the combined immunotherapy group and 12.7 months in the control group. As another DC-based approach, DC may be injected to the tumor site to locally enhance immune response in regional lymph nodes. Fujiwara et al. investigated the intra-tumoral administration of labeled DC combined with systemic chemotherapy involving adriacin, cisplatin and fluorouracil in locally advanced esophageal cancer (87). Scintigraphic images obtained after DC administration demonstrated DC predominantly remaining at the esophageal tumor injection sites, and no DC accumulation in regional lymph nodes was observed. Local DC injection failed to translate into a benefit in terms of overall survival or tumor response. Administration of tumor antigens as a vaccination immunotherapeutic approach may provoke tumor-targeted immuno-response. Yasuda et al. reported 5-year-survival rates of $58.4 \%$ in a phase II study treating 63 ESCC patients with neoadjuvant therapy followed by curative surgery with or without adjuvant vaccination of three HLA-A-24-restricted epitope peptides (88). Adjuvant vaccination induced augmented antigen-specific $\mathrm{CD}^{+} \mathrm{T}$ cell response, and lead to improved local tumor control. The concept of enhancing therapeutic effects of standard treatment regimens by adding vaccination therapy was also investigated in a study by Linuma et al. (89). Concurrent radio-chemotherapy in combination with a HLA-A*2402-restricted multi-peptide vaccine was assessed in 11 advanced and irresectable ESCC patients. The peptide vaccine included the following 5 peptides: TTK protein kinase (TTK), up-regulated lung cancer 10 (URLC10), insulin-like growth factor-II mRNA binding protein 3 (KOC1), vascular endothelial growth factor receptor 1 (VEGFR1) and 2 (VEGFR2). All patients showed peptide-specific cytotoxic T-cell response against at least one of the 5 kinds of peptide antigens. Over $50 \%$ of all treated patients showed complete response.

\section{Gastric Cancer and Adenocarcinoma of the Gastroesophageal Junction}

Gastric cancer is the third leading cause of cancer-related mortality, and the fifth most common cancer worldwide. Incidence rates are highly dependent on geographic regions. Nearly $90 \%$ of all gastric cancer patients present with adenocarcinoma (90). Systematic reduction of major risk factors such as Helicobacter pylori or alimentary features as well as improvements in primary and secondary prevention have led to decreasing incidence and mortality rates in Western countries (91). However, fatality rates remain as high as $70 \%$ (92). Curative therapy options for gastric cancer are partial or complete gastrectomy with lymph node dissection. High cure rates are achieved for stage IA and IB gastric cancer, but the results for advanced stages IIIA and IIIB are poor, and a high percentage of patients are locally irresectable at time of diagnosis $(93,94)$. Five-year overall survival rates in patients diagnosed with advanced or 
metastatic disease are not exceeding 20\% (95). Multimodal treatment involving surgery, chemotherapy and radiotherapy have been the mainstay in the treatment of gastric cancer. Perioperative chemotherapy is well-established, however, radiological response rates to standard regimens are ranging from $60-70 \%$, and histological response rates are markedly lower (96). Multiple mechanisms of chemoresistance were identified in gastric cancer such as drug inactivation via Glutathione S-transferases, apoptosis dysregulation via e.g. BCL-2 family members or PI3K/AKT pathway, drug efflux via ATP-binding cassette transporter or aspects of the microenvironment like hypoxia or extracellular matrix components (97-102).

To enlarge the scope of treatment options in gastric cancer novel immunotherapeutics such as targeted antibodies, checkpoint inhibitors, cytokines, adaptive cell therapies or vaccines have been evaluated in gastric cancer (103). To further enhance the effect of standard multimodal regimens, clinical trials were conducted to investigate the effects of additional immunotherapy.

After showing impressive results in other solid malignancies such as lung cancer and melanoma, checkpoint PD-L1-targeted therapy was also evaluated in adenocarcinoma of the stomach and the gastroesophageal junction. Pembrolizumab is an antibody targeting PD1, and phase Ib KEYNOTE-012 trial was the first clinical trial to investigate pembrolizumab in adenocarcinoma of the gastroesophageal junction (104). A total of 39 PD-L1 positive patients with advanced tumors, and $22 \%$ of the patients had partial clinical response with an overall acceptable toxicity. Based on these promising results, KEYNOTE-059 was developed as a phase II trial evaluating pembrolizumab in advanced adenocarcinoma of the gastroesophageal junction. Cohort 1 evaluated pembrolizumab as third line agent, while the agent was assessed as first line agent in recurrent or metastatic HER-2 positive and PD1 positive gastroesophageal cancer $(105,106)$. In cohort 1 , preliminary results revealed an overall response rate for patients in the third-line setting of $21.3 \%$, and $3.4 \%$ had a complete response. Median progression-free survival was 2 months, and median overall survival was 6 months. In cohort 3 , preliminary results after 14.5 months of follow up showed an overall response rate of $26 \%$. In an up-dated analysis at a median follow-up time of 18 months, progression-free survival was 3.3 months and median overall survival was not reached. Cohort 2 evaluated pembrolizumab combined with cisplatin and fluorouracil as first line therapy in HER-2 negative recurrent or metastatic adenocarcinoma of the gastroesophageal junction (107). Preliminary results of 25 patients at a median follow-up time of 14 months showed an overall response rate of $60 \%$ while median progression-free survival was 7 months and median overall survival was 14 months. Further trials of combined pembrolizumab and chemotherapy are currently recruiting. KEYNOTE-062 is a phase III trial evaluating pembrolizumab alone versus pembrolizumab in combination with cisplatin and fluorouracil versus chemotherapy alone as first line therapy in PD-L1 positive and HER-2 negative advanced adenocarcinoma of the gastro-esophageal junction (108). Further trials currently assess the combination of pembrolizumab, trastuzumab, cisplatin and capecitabine as first line treatment in adenocarcinoma of the stomach and the gastroesophageal junction (NCT02954536 and NCT02901301).

Nivolumab as a monoclonal PD-1 antibody was assessed in a recent Asian phase III study of patients with chemorefractory advanced adenocarcinoma of the stomach or the gastro-esophageal junction (109). Nivolumab treatment resulted in 12 -months overall survival of $26.2 \%$ compared to $10.9 \%$ in patients receiving placebo. Grade III to IV toxicity of nivolumab was acceptable with $10 \%$ in a patient cohort with a history of multiple pre-treatment regimens. Interestingly, the study population was unselected for PD-L1 expression. In a retrospective analysis, PD-L1 expression was reviewed in $40 \%$ of the patients and showed no correlation with treatment outcome. Further studies are needed to verify the proportion of patients profiting from PD-L1 treatment and potential further determinants of PD-L1 therapy outcome. PDL1 targeted therapy is currently investigated in several phase III trials such as the JAVELIN 100 gastric trial evaluating the effect of avelumab in locally advanced or metastatic gastric or gastro-esophageal junction cancer.

HER-2 is an established prognostic factor in gastric cancer (110). Trastuzumab, a monoclonal antibody specific to HER2 combined with platinum based chemotherapy demonstrated efficacy in terms of overall survival, progression-free survival and tumor response for gastric cancer patients (111). Outcomes from a very recent multicentre study suggests that irinotecan based chemotherapy, which demonstrates better outcomes than platinum based therapy, can be used safely and effectively with trastuzumab in gastric and gastro-esophageal cancer patients (112). EGFR was identified as another potential target overexpressed in over $30 \%$ of gastric cancer patients (113). However, current phase III trials evaluating EGFR targeted therapy with cetuximab concurrent to chemotherapy demonstrated increased toxicity and no benefit in terms of overall or progression-free survival in patients with advanced gastric cancer (114). Antibodies targeting VEGFR showed promising results in malignancies of the stomach and the gastroesophageal junction. The phase III AVAGAST trial detected an improvement in progression-free survival and tumor response rate for patients receiving combined chemotherapy and bevacizumab for locally advanced gastric cancer (42). Ramucirumab as a monoclonal antibody VEGFR2 antagonist was evaluated in the phase III RAINBOW trial in patients with advanced gastric or gastro-esophageal junction adenocarcinoma (115). Patients received either paclitaxel plus ramucirumab or paclitaxel plus placebo, and ramucirumab treatment resulted in prolonged overall survival (9.6 months 
versus 7.4 months) while toxicity was moderate. Also apatinib, a VEGFR-2 tyrosine kinase inhibitor, was demonstrated to improve overall and progression-free survival in a phase III trial of patients with chemotherapy-refractory advanced or metastatic adenocarcinoma of the stomach or gastroesophageal junction (116). A current phase III trial is ongoing to assess ramucirumab as a first-line agent combined with cisplatin and capecitabine or fluorouracil in gastroesophageal and gastric adenocarcinoma (117).

Cytokine-induced killer cell-based therapy provides an immunotherapeutic approach involving anti-tumor effects via direct cell-cell-contact-mediated apoptosis and secretion of cytokines (118). To further boost the effects of cytokineinduced killer cells, the approach may be combined with tumor-specific dendritic cells presenting tumor antigens and orchestrating T-cell response. Several clinical studies proved potent anti-tumor effects in patients with both resected and locally advanced gastric cancer receiving standard chemotherapeutic agents and cytokine-induced killer cells (119-121). Mu et al. conducted a meta-analysis on 1,735 gastric cancer patients treated with standard chemotherapy and cytokine-induced killer cell approaches with or without dendritic cell-therapy versus standard chemotherapy alone (122). 17 trials evaluating patients with resectable and locally advanced disease undergoing different chemotherapy regimens were included. The authors detected a significant increase in overall and disease-free survival in patients receiving multimodal chemotherapy and cytokine-induced killer cell treatment. Notably, response rates $(p=0.002)$, disease control rates $(p=0.0007)$, and quality of life $(p=0.0008)$ were also improved in patients with combined treatment. The authors detected an augmented immune response and a decrease in tumor markers in the multimodal group. The most frequently reported side effect of combined cytokine-induced killer cell treatment and chemotherapy was fever. Interestingly, additional immunotherapy distinctly alleviated common chemotherapy side effects such as leucopenia, thrombocytopenia or nausea.

Vaccination approaches are potential options to augment immunogenic antitumor response. Feasibility studies evaluated vaccination with tumor-specific antigens in gastric cancer patients $(123,124)$. Vaccination was well-tolerated and showed an increase in antitumor immuno-response. Heat shock proteins such as glycoprotein 96, which comprises a wide range of tumor-specific antigens, qualified as cancer vaccine in different entities including gastro-intestinal malignancies $(125,126)$. Glycoprotein 96 protein complexes interact with dendritic cells, induce maturation processes in these cells and provoke cytokine production. Zhang et al. conducted a phase II trial assessing combined chemotherapy and glycoprotein 96 vaccination versus chemotherapy alone as adjuvant treatment in gastric cancer (127). The authors reported a strong increase in tumor-specific immuno- response in patients receiving combined treatment. 2-year disease-free survival was improved in patients treated with additional glycoprotein 96 (66.5\% vs. 34.9\%, $p=0.045)$, but the combined approach failed to translate into prolonged 2year overall survival. The authors proposed to particularly apply combined chemotherapy and glycoprotein 96 vaccination in patients with less aggressive disease and a less immunosuppressive tumor microenvironment. Ajani et al. evaluated combined treatment of cisplatin/fluorouracil and G17DT vaccination in a multi-center phase II study of advanced gastric or gastroesophageal cancer (128). G17DT was identified as an immunogenic agent eliciting specific anti-gastrin antibodies reducing growth and metastatic potential in xenograft models (129). A total of 103 patients were included in the combined chemo-vaccination trial, and $69 \%$ showed immunogenic response. Median time to progression as well as median overall survival (10.3 months vs. 3.4 months, $p=0.0001$ ) were prolonged in responders compared to non-responders. Vaccination was an independent prognostic factor. Masuzawa et al. combined S1/cisplatin chemotherapy and vaccination with human leukocyte antigen (HLA)-A24-restricted human vascular endothelial growth factor receptor 1 (VEGFR1)-1084 and VEGFR2-169 in a phase I/II trial (130). Overall, 22 patients with advanced gastric cancer were included. They reported a considerable disease control rate of $100 \%$ after two cycles. Median time to progression was 9.6 months and median overall survival was 14.2 months.

\section{Potential Obstacles and Future Perspectives}

Multimodal concepts involving standard therapies such as chemotherapy and radiotherapy combined with immunotherapy may be potent therapeutic approaches to overcome tumor resistance in upper gastrointestinal malignancies. Mortality rates in esophageal and gastric cancer showed only minor improvements over the past years, and novel treatment strategies are needed. Several clinical trials demonstrated promising results for multimodal immunotherapy in upper gastrointestinal cancer. Despite a growing body of encouraging data, some major obstacles of immunotherapy have to be addressed. The effects of immunotherapy may be distinctly altered by not only local tumor site-associated, but also systemic immunosuppression. Several components of the tumor microenvironment play an essential role in modifying immunogenic response and their function and complex interaction network is not wellunderstood yet. Attempts have been made to measure immunotherapy-induced immunogenic response. However, uncertainties are raised whether and which systemic markers mirror actual tumor control. The optimal delivery of immunotherapy to evoke the best possible both systemic, but also local antitumor response remains controversial. To date 
most trials assessing multimodal immunotherapy are phase I or II trials. Notably, reported toxicity rates were low and partly impressive disease control rates were reported. This makes multimodal immunotherapy an interesting option for patients with advanced or refractory disease. The assessment of these first trials is however hindered by various application methods reported in different trials. Even in well-established immunotherapeutic concepts such as dendritic cell-based therapy or cytokine-induced killer cell therapy, no standard application protocols have been established yet. More large multi-center phase III trials directly comparing standard treatment versus multimodal immunotherapy are needed to verify the benefit of additional application of immunogenic agents. Future trials should be carefully designed to evaluate multimodal immunotherapy in different treatment settings of gastrointestinal malignancies.

A major issue to address is adequate patient selection for multimodal immunotherapy. Mainly for patients treated with checkpoint inhibitors, adequate patient selection and the identification of responding and non-responding patient subgroups is warranted. Parameters determining treatment response to other immunotherapeutic options are also uncertain at present. Further attempts should be made to identify ideal candidates for specific immunotherapeutic approaches, including determination of genomic, epigenomic and other 'omics' profiles associated with therapy response.

Despite these challenges, data from current studies support continued research efforts into understanding immunotherapeutic mechanisms and their interaction with standard therapies. There is scope for multimodal immunotherapy to become standard practice for overcoming tumor resistance in upper gastrointestinal malignancies.

\section{Conclusion}

Immunotherapeutic approaches are on the rise in esophageal and gastric cancer. PD-L1-targeted therapy has been demonstrated to be a potent option even in patients with multiple courses of pre-treatment. Future studies should address the effect of those agents used in earlier treatment lines, further evaluate combination regimens with standard chemotherapy, and identify optimal patient cohorts for PD-L1targeted therapy. Cytokine-induced killer cell therapy and vaccination approaches showed promising effects when combined with chemotherapy and should be further investigated. Patients not responding to classical approaches can be candidates for multimodal immunotherapeutic approaches. In an adjuvant setting, additional immunotherapy may yield beneficial results. Future studies evaluating combining standard multimodal treatment approaches with targeted immunotherapy are warranted for improving treatment response and patient prognosis in esophageal and gastric cancer.

\section{References}

1 Haq S, Ali S, Mohammad R and Sarkar FH: The complexities of epidemiology and prevention of gastrointestinal cancers. Int J Mol Sci 13: 12556-12572, 2012.

2 Pennathur A, Gibson MK, Jobe BA and Luketich JD: Oesophageal carcinoma. The Lancet 381: 400-412, 2013.

3 Orditura M, Galizia G, Sforza V, Gambardella V, Fabozzi A, Laterza MM, Andreozzi F, Ventriglia J, Savastano B and Mabilia A: Treatment of gastric cancer. World J Gastroenterol WJG 20: 1635-1649, 2014.

4 Lillemoe KD, Yeo CJ and Cameron JL: Pancreatic cancer: state-of-the-art care. CA Cancer J Clin 50: 241-268, 2000.

5 Choi AH, Kim J and Chao J: Perioperative chemotherapy for resectable gastric cancer: MAGIC and beyond. World J Gastroenterol WJG 21: 7343-7348, 2015.

6 Gwynne S, Wijnhoven B, Hulshof M and Bateman A: Role of chemoradiotherapy in oesophageal cancer - adjuvant and neoadjuvant therapy. Clin Oncol 26: 522-532, 2014.

7 Katz MH, Fleming JB, Bhosale P, Varadhachary G, Lee JE, Wolff R, Wang H, Abbruzzese J, Pisters PW and Vauthey J: Response of borderline resectable pancreatic cancer to neoadjuvant therapy is not reflected by radiographic indicators. Cancer 118: 5749-5756, 2012.

8 Davidson $\mathrm{M}$ and Chau I: Multimodality treatment of operable gastric and oesophageal adenocarcinoma: evaluating neoadjuvant, adjuvant and perioperative approaches. Expert Rev Anticancer Ther 18: 1-12, 2018.

9 van Rossum PS, Mohammad NH, Vleggaar FP and van Hillegersberg R: Treatment for unresectable or metastatic oesophageal cancer: current evidence and trends. Nat Rev Gastroenterol Hepatol 15: 235-249, 2017.

10 Hoeppner J, Lordick F, Brunner T, Glatz T, Bronsert P, Röthling N, Schmoor C, Lorenz D, Ell C and Hopt UT: ESOPEC: prospective randomized controlled multicenter phase III trial comparing perioperative chemotherapy (FLOT protocol) to neoadjuvant chemoradiation (CROSS protocol) in patients with adenocarcinoma of the esophagus (NCT02509286). BMC Cancer 16: 503, 2016.

11 Schulz C, Kullmann F, Kunzmann V, Fuchs M, Geissler M, Vehling-Kaiser U, Stauder H, Wein A, Al-Batran S and Kubin T: NeoFLOT: multicenter phase II study of perioperative chemotherapy in resectable adenocarcinoma of the gastroesophageal junction or gastric adenocarcinoma - very good response predominantly in patients with intestinal type tumors. Int J Cancer 137: 678-685, 2015.

12 Al-Batran SE, Hofheinz RD, Pauligk C, Kopp HG, Haag GM, Luley KB, Meiler J, Homann N, Lorenzen S and Schmalenberg $\mathrm{H}$ : Histopathological regression after neoadjuvant docetaxel, oxaliplatin, fluorouracil, and leucovorin versus epirubicin, cisplatin, and fluorouracil or capecitabine in patients with resectable gastric or gastrooesophageal junction adenocarcinoma (FLOT4-AIO): results from the phase 2 part of a multicentre, open-label, randomised phase 2/3 trial. Lancet Oncol 17: 1697-1708, 2016.

13 Barbee MS, Ogunniyi A, Horvat TZ and Dang TO: Current status and future directions of the immune checkpoint inhibitors ipilimumab, pembrolizumab, and nivolumab in oncology. Ann Pharmacother 49: 907-937, 2015. 
14 Ito A, Kondo S, Tada K and Kitano S: Clinical development of immune checkpoint inhibitors. BioMed Res Int 2015: 605478, 2015.

15 Herbst RS, Baas P, Kim DW, Felip E, Pérez-Gracia JL, Han JY, Molina J, Kim JH, Arvis CD and Ahn MJ: Pembrolizumab versus docetaxel for previously treated, PD-L1-positive, advanced non-small-cell lung cancer (KEYNOTE-010): a randomised controlled trial. The Lancet 387: 1540-1550, 2016.

16 Horn L, Spigel DR, Vokes EE, Holgado E, Ready N, Steins M, Poddubskaya E, Borghaei H, Felip E and Paz-Ares L: Nivolumab versus docetaxel in previously treated patients with advanced non-small-cell lung cancer: Two-year outcomes from two randomized, open-label, phase III trials (CheckMate 017 and CheckMate 057). J Clin Oncol 35: 3924-3933, 2017.

17 Schachter J, Ribas A, Long GV, Arance A, Grob JJ, Mortier L, Daud A, Carlino MS, McNeil C and Lotem M: Pembrolizumab versus ipilimumab for advanced melanoma: final overall survival results of a multicentre, randomised, open-label phase 3 study (KEYNOTE-006). The Lancet 390: 1853-1862, 2017.

18 Coit DG, Thompson JA, Algazi A, Andtbacka R, Bichakjian CK, Carson WE, Daniels GA, DiMaio D, Ernstoff M and Fields RC: Melanoma, version 2.2016, NCCN clinical practice guidelines in oncology. J Natl Compr Canc Netw 14: 450-473, 2016.

19 Ettinger DS, Wood DE, Aisner DL, Akerley W, Bauman J, Chirieac LR, D'Amico TA, DeCamp MM, Dilling TJ and Dobelbower M: Non-small cell lung cancer, version 5.2017, NCCN clinical practice guidelines in oncology. J Natl Compr Canc Netw 15: 504-535, 2017.

20 Ikemoto T, Yamaguchi T, Morine Y, Imura S, Soejima Y, Fujii M, Maekawa Y, Yasutomo K and Shimada M: Clinical roles of increased populations of Foxp3+ CD4+ T cells in peripheral blood from advanced pancreatic cancer patients. Pancreas 33: 386-390, 2006.

21 Toomey PG, Vohra NA, Ghansah T, Sarnaik AA and PilonThomas SA: Immunotherapy for gastrointestinal malignancies. Cancer Control 20: 32-42, 2013.

22 Wang J, Reiss KA, Khatri R, Jaffee E and Laheru D: Immune therapy in GI malignancies: a review. J Clin Oncol 33: 17451753, 2015.

23 Moehler M, Delic M, Goepfert K, Aust D, Grabsch HI, Halama N, Heinrich B, Julie C, Lordick F and Lutz MP: Immunotherapy in gastrointestinal cancer: Recent results, current studies and future perspectives. Eur J Cancer 59: 160-170, 2016.

24 Cappello P and Novelli F: Next generation of cancer immunotherapy calls for combination. Oncoscience 31: 19-20, 2017.

25 Scott AM, Wolchok JD and Old LJ: Antibody therapy of cancer. Nat Rev Cancer 12: 278-287, 2012.

26 Scott LJ: Nivolumab: a review in advanced melanoma. Drugs 75: 1413-1424, 2015.

27 La-Beck NM, Jean GW, Huynh C, Alzghari SK and Lowe DB: Immune checkpoint inhibitors: new insights and current place in cancer therapy. Pharmacother J Hum Pharmacol Drug Ther 35: 963-976, 2015.

28 Shimanovsky A and Dasanu CA: Updates on immunotherapy in non-small cell lung cancer. Expert Opin Biol Ther 14: 411418,2014

29 Samson P and Lockhart AC: Biologic therapy in esophageal and gastric malignancies: current therapies and future directions. J Gastrointest Oncol 8: 418-429, 2017.
30 Bronte G, Cicero G, Cusenza S, Galvano A, Musso E, Rizzo S, Sortino G, Roselli M, Bazan V and Fiorentino E: Monoclonal antibodies in gastrointestinal cancers. Expert Opin Biol Ther 13: 889-900, 2013.

31 Slamon D, Clark G, Wong S, Levin W, Ullrich A and McGuire W: Human breast cancer: correlation of relapse and survival with amplification of the HER-2/neu oncogene. Science 235: 177-182, 1987.

32 Ross JS and McKenna BJ: The HER-2/neu oncogene in tumors of the gastrointestinal tract. Cancer Invest 19: 554-568, 2001.

33 Chan DS, Twine CP and Lewis WG: Systematic review and meta-analysis of the influence of HER2 expression and amplification in operable oesophageal cancer. J Gastrointest Surg 16: 1821-1829, 2012.

34 Bang YJ, Van Cutsem E, Feyereislova A, Chung HC, Shen L, Sawaki A, Lordick F, Ohtsu A, Omuro Y and Satoh T: Trastuzumab in combination with chemotherapy versus chemotherapy alone for treatment of HER2-positive advanced gastric or gastro-oesophageal junction cancer (ToGA): a phase 3, open-label, randomised controlled trial. The Lancet 376: 687697, 2010.

35 Hecht JR, Bang YJ, Qin SK, Chung HC, Xu JM, Park JO, Jeziorski K, Shparyk Y, Hoff PM and Sobrero A: Lapatinib in combination with capecitabine plus oxaliplatin in human epidermal growth factor receptor 2-positive advanced or metastatic gastric, esophageal, or gastroesophageal adenocarcinoma: TRIO-013/LOGiC - a randomized phase III trial. J Clin Oncol 34: 443-451, 2015.

36 Swain SM, Kim SB, Cortés J, Ro J, Semiglazov V, Campone M, Ciruelos E, Ferrero JM, Schneeweiss A and Knott A: Pertuzumab, trastuzumab, and docetaxel for HER2-positive metastatic breast cancer (CLEOPATRA study): overall survival results from a randomised, double-blind, placebo-controlled, phase 3 study. Lancet Oncol 14: 461-471, 2013.

37 Yamashita-Kashima Y, Iijima S, Yorozu K, Furugaki K, Kurasawa M, Ohta M and Fujimoto-Ouchi K: Pertuzumab in combination with trastuzumab shows significantly enhanced antitumor activity in HER2-positive human gastric cancer xenograft models.Clin Cancer Res 17: 5060-5070, 2011.

38 Thuss-Patience PC, Shah MA, Ohtsu A, Van Cutsem E, Ajani JA, Castro H, Mansoor W, Chung HC, Bodoky G and Shitara $\mathrm{K}$ : Trastuzumab emtansine versus taxane use for previously treated HER2-positive locally advanced or metastatic gastric or gastro-oesophageal junction adenocarcinoma (GATSBY): an international randomised, open-label, adaptive, phase 2/3 study. Lancet Oncol 18: 640-653, 2017.

39 Keating GM: Bevacizumab: a review of its use in advanced cancer. Drugs 74: 1891-1925, 2014.

40 Dreikhausen L, Blank S, Sisic L, Heger U, Weichert W, Jäger D, Bruckner T, Giese N, Grenacher L and Falk C: Association of angiogenic factors with prognosis in esophageal cancer. BMC Cancer 15: 121, 2015.

41 Blank S, Deck C, Dreikhausen L, Weichert W, Giese N, Falk C, Schmidt T and Ott K: Angiogenic and growth factors in gastric cancer. J Surg Res 194: 420-429, 2015.

42 Ohtsu A, Shah MA, Van Cutsem E, Rha SY, Sawaki A, Park SR, Lim HY, Yamada Y, Wu J and Langer B: Bevacizumab in combination with chemotherapy as first-line therapy in advanced gastric cancer: a randomized, double-blind, placebocontrolled phase III study. J Clin Oncol 29: 3968-3976, 2011. 
43 Fuchs CS, Tomasek J, Yong CJ, Dumitru F, Passalacqua R, Goswami C, Safran H, dos Santos LV, Aprile G and Ferry DR: Ramucirumab monotherapy for previously treated advanced gastric or gastro-oesophageal junction adenocarcinoma (REGARD): an international, randomised, multicentre, placebocontrolled, phase 3 trial. The Lancet 383: 31-39, 2014.

44 Topalian SL, Taube JM, Anders RA and Pardoll DM: Mechanism-driven biomarkers to guide immune checkpoint blockade in cancer therapy. Nat Rev Cancer 16: 275-287, 2016.

45 Larkin J, Chiarion-Sileni V, Gonzalez R, Grob JJ, Cowey CL, Lao CD, Schadendorf D, Dummer R, Smylie M and Rutkowski P: Combined nivolumab and ipilimumab or monotherapy in untreated melanoma. N Engl J Med 373: 23-34, 2015.

46 Garon EB, Rizvi NA, Hui R, Leighl N, Balmanoukian AS, Eder JP, Patnaik A, Aggarwal $C$, Gubens $M$ and Horn L: Pembrolizumab for the treatment of non-small-cell lung cancer. N Engl J Med 372: 2018-2028, 2015.

47 Tamura T, Ohira M, Tanaka H, Muguruma K, Toyokawa T, Kubo N, Sakurai K, Amano R, Kimura K and Shibutani M: Programmed death-1 ligand-1 (PDL1) expression is associated with the prognosis of patients with stage II/III gastric cancer. Anticancer Res 35: 5369-5376, 2015.

48 Zhang M, Dong Y, Liu H, Wang Y, Zhao S, Xuan Q and Zhang $\mathrm{Q}$ : The clinicopathological and prognostic significance of PDL1 expression in gastric cancer: a meta-analysis of 10 studies with 1,901 patients. Sci Rep 6: 37933, 2016.

49 Yuan J, Zhang J, Zhu Y, Li N, Tian T, Li Y, Li Y, Li Z, Lai Y and Gao J: Programmed death-ligand-1 expression in advanced gastric cancer detected with RNA in situ hybridization and its clinical significance. Oncotarget 7: 39671-39679, 2016.

50 Bonini $\mathrm{C}$ and Mondino A: Adoptive T-cell therapy for cancer: The era of engineered T cells. Eur J Immunol 45: 2457-2469, 2015.

51 Feldman SA, Assadipour Y, Kriley I, Goff SL and Rosenberg SA: Adoptive cell therapy - tumor-infiltrating lymphocytes, Tcell receptors, and chimeric antigen receptors. Semin Oncol 42: 626-639, 2015.

52 Rosenberg SA, Lotze MT, Muul LM, Chang AE, Avis FP, Leitman S, Linehan WM, Robertson CN, Lee RE and Rubin JT: A progress report on the treatment of 157 patients with advanced cancer using lymphokine-activated killer cells and interleukin-2 or high-dose interleukin-2 alone. N Engl J Med 316: 889-897, 1987.

53 Besser MJ, Shapira-Frommer R, Treves AJ, Zippel D, Itzhaki O, Hershkovitz L, Levy D, Kubi A, Hovav E and Chermoshniuk $\mathrm{N}$ : Clinical responses in a phase II study using adoptive transfer of short-term cultured tumor infiltration lymphocytes in metastatic melanoma patients. Clin Cancer Res 16: 2646-2655, 2010.

54 Amedei A, Niccolai E and D'Elios MM: T cells and adoptive immunotherapy: recent developments and future prospects in gastrointestinal oncology. Clin Dev Immunol 2011: 320571, 2011.

55 Kim YJ, Lim J, Kang JS, Kim HM, Lee HK, Ryu HS, Kim JY, Hong JT, Kim Y and Han SB: Adoptive immunotherapy of human gastric cancer with ex vivo expanded T cells. Arch Pharm Res 33: 1789-1795, 2010.

56 Patel SJ, Sanjana NE, Kishton RJ, Eidizadeh A, Vodnala SK, Cam M, Gartner JJ, Jia L, Steinberg SM and Yamamoto TN: Identification of essential genes for cancer immunotherapy. Nature 548: 537-542, 2017.
57 Zhu J, de Tenbossche CGP, Cané S, Colau D, van Baren N, Lurquin C, Schmitt-Verhulst AM, Liljeström P, Uyttenhove C and Van den Eynde BJ: Resistance to cancer immunotherapy mediated by apoptosis of tumor-infiltrating lymphocytes. Nat Commun 8: 1404, 2017.

58 Kimura Y, Tsukada J, Tomoda T, Takahashi H, Imai K, Shimamura K, Sunamura M, Yonemitsu Y, Shimodaira S and Koido S: Clinical and immunologic evaluation of dendritic cell-based immunotherapy in combination with gemcitabine and/or S-1 in patients with advanced pancreatic carcinoma. Pancreas 41: 195-205, 2012.

59 Anguille S, Smits EL, Lion E, van Tendeloo VF and Berneman $\mathrm{ZN}$ : Clinical use of dendritic cells for cancer therapy. Lancet Oncol 15: e257-e267, 2014.

60 Bhargava A, Mishra D, Banerjee S and Mishra PK: Engineered dendritic cells for gastrointestinal tumor immunotherapy: opportunities in translational research. J Drug Target 21: 126136, 2013.

61 Galetto A, Contarini M, Sapino A, Cassoni P, Consalvo E, Forno S, Pezzi C, Barnaba V, Mussa A and Matera L: Ex vivo host response to gastrointestinal cancer cells presented by autologous dendritic cells. J Surg Res 100: 32-38, 2001.

62 Rong Y, Qin X, Jin D, Lou W, Wu L, Wang D, Wu W, Ni X, Mao Z and Kuang T: A phase I pilot trial of MUC1-peptidepulsed dendritic cells in the treatment of advanced pancreatic cancer. Clin Exp Med 12: 173-180, 2012.

63 Kono K, Takahashi A, Sugai H, Fujii H, Choudhury AR, Kiessling $\mathrm{R}$ and Matsumoto Y: Dendritic cells pulsed with HER-2/neu-derived peptides can induce specific T-cell responses in patients with gastric cancer. Clin Cancer Res 8 : 3394-3400, 2002.

64 Tanaka F, Haraguchi N, Isikawa K, Inoue H and Mori M: Potential role of dendritic cell vaccination with MAGE peptides in gastrointestinal carcinomas. Oncol Rep 20: 1111-1116, 2008.

65 Bianchi G, Borgonovo G, Pistoia V and Raffaghello L: Immunosuppressive cells and tumour microenvironment: focus on mesenchymal stem cells and myeloid derived suppressor cells. Histol Histopathol 26: 941, 2011.

66 Apte M, Xu Z, Pothula S, Goldstein D, Pirola R and Wilson J: Pancreatic cancer: the microenvironment needs attention too! Pancreatology 15: S32-S38, 2015.

67 Tan G, Wang Z, Zhang X, Cai Z and Zhang J: Induction of CTLs by DCs pulsed with K-ras mutant peptide on the surface of nanoparticles in the treatment of pancreatic cancer. Oncol Rep 26: 215-221, 2011.

68 Zhang Z, Guo Y and Feng S-S: Nanoimmunotherapy: application of nanotechnology for sustained and targeted delivery of antigens to dendritic cells. Nanomedicine 7: 1-4, 2011.

69 Arnal MJD, Arenas ÁF and Arbeloa ÁL: Esophageal cancer: Risk factors, screening and endoscopic treatment in Western and Eastern countries. World J Gastroenterol 21: 7933-7943, 2015.

70 Malhotra GK, Yanala U, Ravipati A, Follet M, Vijayakumar M and Are C: Global trends in esophageal cancer. J Surg Oncol 115: 564-579, 2017.

71 Zhang Y: Epidemiology of esophageal cancer. World J Gastroenterol 19: 5598-5606, 2013.

72 Reynolds JV, Muldoon C, Hollywood D, Ravi N, Rowley S, O'Byrne K, Kennedy J and Murphy TJ: Long-term outcomes following neoadjuvant chemoradiotherapy for esophageal cancer. Ann Surg 245: 707-716, 2007. 
73 Bollschweiler E, Hölscher AH, Schmidt M and Warnecke-Eberz $\mathrm{U}$ : Neoadjuvant treatment for advanced esophageal cancer: response assessment before surgery and how to predict response to chemoradiation before starting treatment. Chin J Cancer Res 27: 221-230, 2015.

74 Davidson M and Chau I: Immunotherapy for oesophagogastric cancer. Expert Opin Biol Ther 16: 1197-1207, 2016.

75 Belkhiri A and El-Rifai W: Advances in targeted therapies and new promising targets in esophageal cancer. Oncotarget 6: 1348-1358, 2015.

76 Xie J, Wang J, Cheng S, Zheng L, Ji F, Yang L, Zhang Y and $\mathrm{Ji} \mathrm{H}$ : Expression of immune checkpoints in $\mathrm{T}$ cells of esophageal cancer patients. Oncotarget 7: 63669-63678, 2016.

77 Hakenberg OW: Nivolumab for the treatment of bladder cancer. Expert Opin Biol Ther 17: 1309-1315, 2017.

78 Guibert $\mathrm{N}$ and Mazières $\mathrm{J}$ : Nivolumab for treating non-small cell lung cancer. Expert Opin Biol Ther 15: 1789-1797, 2015.

79 Kudo T, Hamamoto Y, Kato K, Ura T, Kojima T, Tsushima T, Hironaka S, Hara $\mathrm{H}$, Satoh $\mathrm{T}$ and Iwasa $\mathrm{S}$ : Nivolumab treatment for oesophageal squamous-cell carcinoma: an openlabel, multicentre, phase 2 trial. Lancet Oncol 18: 631-639, 2017.

80 Doi T, Piha-Paul SA, Jalal SI, Mai-Dang H, Saraf S, Koshiji M, Csiki I and Bennouna J: Updated results for the advanced esophageal carcinoma cohort of the phase Ib KEYNOTE-028 study of pembrolizumab (MK-3475). J Clin Oncol 34: 7-7, 2016.

81 Nagaraja V, Shaw N, Morey A, Cox M and Eslick G: HER2 expression in oesophageal carcinoma and Barrett's oesophagus associated adenocarcinoma: An Australian study. Eur J Surg Oncol EJSO 42: 140-148, 2016.

82 Safran H, DiPetrillo T, Akerman P, Ng T, Evans D, Steinhoff M, Benton D, Purviance J, Goldstein L and Tantravahi U: Phase I/II study of trastuzumab, paclitaxel, cisplatin and radiation for locally advanced, HER2 overexpressing, esophageal adenocarcinoma. Int J Radiat Oncol Biol Phys 67: 405-409, 2007.

83 Trombetta ES, Ebersold M, Garrett W, Pypaert M and Mellman I: Activation of lysosomal function during dendritic cell maturation. Science 299: 1400-1403, 2003.

84 Guo GH, Chen SZ, Yu J, Zhang J, Luo LL, Xie LH, Su ZJ, Dong $\mathrm{HM}, \mathrm{Xu} \mathrm{H}$ and $\mathrm{Wu} \mathrm{LB}$ : In vivo anti-tumor effect of hybrid vaccine of dendritic cells and esophageal carcinoma cells on esophageal carcinoma cell line 109 in mice with severe combined immune deficiency. World J Gastroenterol WJG 14: 1167-1174, 2008.

85 Narita M, Kanda T, Abe T, Uchiyama T, Iwafuchi M, Zheng Z, Liu A, Kaifu T, Kosugi S and Minagawa M: Immune responses in patients with esophageal cancer treated with SART1 peptide-pulsed dendritic cell vaccine. Int J Oncol 46: 1699-1709, 2015

86 Yan L, Wu M, Ba N, Wang L, Zhang H, Shi G, Zhang Z and Wang X: Efficacy of dendritic cell-cytokine-induced killer immunotherapy plus intensity-modulated radiation therapy in treating elderly patients with esophageal carcinoma. Genet Mol Res 14: 898-905, 2015.

87 Fujiwara S, Wada H, Miyata H, Kawada J, Kawabata R, Nishikawa H, Gnjatic S, Sedrak C, Sato E and Nakamura Y: Clinical trial of the intratumoral administration of labeled DC combined with systemic chemotherapy for esophageal cancer. J Immunother 35: 513-521, 2012.
88 Yasuda T, Nishiki K, Yoshida K, Shiraishi O, Iwama M, Kato H, Yasuda A, Shinkai M, Chiba Y, Okuno K and Nakamura Y: Cancer peptide vaccine to suppress postoperative recurrence in esophageal SCC patients with induction of antigen-specific CD8+ T cell. J Clin Oncol 35: e14635-e14635, 2017.

89 Iinuma H, Fukushima R, Inaba T, Tamura J, Inoue T, Ogawa E, Horikawa M, Ikeda Y, Matsutani N and Takeda K: Phase I clinical study of multiple epitope peptide vaccine combined with chemoradiation therapy in esophageal cancer patients. J Transl Med 12: 84, 2014.

90 Kelley JR and Duggan JM: Gastric cancer epidemiology and risk factors. J Clin Epidemiol 56: 1-9, 2003.

91 Fock K: The epidemiology and prevention of gastric cancer. Aliment Pharmacol Ther 40: 250-260, 2014.

92 Guggenheim DE and Shah MA: Gastric cancer epidemiology and risk factors. J Surg Oncol 107: 230-236, 2013.

$93 \mathrm{Ku} \mathrm{GY}$ and Ilson DH: Management of gastric cancer. Curr Opin Gastroenterol 30: 596-602, 2014.

94 Santoro R, Ettorre GM and Santoro E: Subtotal gastrectomy for gastric cancer. World J Gastroenterol WJG 20: 13667-13680, 2014.

95 Kalnina Z, Meistere I, Kikuste I, Tolmanis I, Zayakin P and Linē A: Emerging blood-based biomarkers for detection of gastric cancer. World J Gastroenterol 21: 11636-11653, 2015.

96 Kurokawa Y, Shibata T, Sasako M, Sano T, Tsuburaya A, Iwasaki Y and Fukuda H: Validity of response assessment criteria in neoadjuvant chemotherapy for gastric cancer (JCOG0507-A). Gastric Cancer 17: 514-521, 2014.

97 Sun L, Liu L, Liu X, Wang Y, Li M, Yao L, Yang J, Ji G, Guo $\mathrm{C}$ and Pan Y: Gastric cancer cell adhesion to laminin enhances acquired chemotherapeutic drug resistance mediated by MGr1Ag/37LRP. Oncol Rep 32: 105-114, 2014.

98 Isobe T, Aoyagi K, Koufuji K, Shirouzu K, Kawahara A, Taira $\mathrm{T}$ and Kage M: Clinicopathological significance of hypoxiainducible factor- 1 alpha (HIF-1 $\alpha$ ) expression in gastric cancer. Int J Clin Oncol 18: 293-304, 2013.

99 Yu H, Ai Y, Yu L, Zhou X, Liu J, Li J, Xu X, Liu S, Chen J and Liu F: Phosphoinositide 3-kinase/Akt pathway plays an important role in chemoresistance of gastric cancer cells against etoposide and doxorubicin induced cell death. Int J Cancer 122: 433-443, 2008.

100 Geng M, Wang L and Li P: Correlation between chemosensitivity to anticancer drugs and Bcl-2 expression in gastric cancer. Int J Clin Exp Pathol 6: 2554-2559, 2013.

101 da Graça Rocha G, Oliveira RR, Kaplan MAC and Gattass CR: $3 \beta$-Acetyl tormentic acid reverts MRP1/ABCC1 mediated cancer resistance through modulation of intracellular levels of GSH and inhibition of GST activity. Eur J Pharmacol 741: 140149,2014

102 Yu P, Du Y, Cheng X, Yu Q, Huang L and Dong R: Expression of multidrug resistance-associated proteins and their relation to postoperative individualized chemotherapy in gastric cancer. World J Surg Oncol 12: 307, 2014.

103 Grierson P, Lim KH and Amin M: Immunotherapy in gastrointestinal cancers. J Gastrointest Oncol 8: 474-484, 2017.

104 Muro K, Chung HC, Shankaran V, Geva R, Catenacci D, Gupta S, Eder JP, Golan T, Le DT and Burtness B: Pembrolizumab for patients with PD-L1-positive advanced gastric cancer (KEYNOTE-012): a multicentre, open-label, phase $1 \mathrm{~b}$ trial. Lancet Oncol 17: 717-726, 2016. 
105 Catenacci Daniel V, Wainberg Z, Fuchs Charles S, Garrido M, Bang YJ, Muro K, Savage M, Wang J, Koshiji M and Dalal Rita P: LBA-009KEYNOTE-059 cohort 3: safety and efficacy of pembrolizumab monotherapy for first-line treatment of patients (pts) with PD-L1-positive advanced gastric/gastroesophageal (G/GEJ) cancer. Ann Oncol 28, 2017. https://doi.org/10.1093/ annonc/mdx302.008. [Epub ahead of print]

106 Fuchs CS, Doi T, Jang RWJ, Muro K, Satoh T, Machado M, Sun W, Jalal SI, Shah MA and Metges J-P: KEYNOTE-059 cohort 1: Efficacy and safety of pembrolizumab (pembro) monotherapy in patients with previously treated advanced gastric cancer. J Clin Oncol 35: 4003-4003, 2017.

107 Bang YJ, Muro K, Fuchs CS, Golan T, Geva R, Hara H, Jalal SI, Borg C, Doi T and Wainberg ZA: KEYNOTE-059 cohort 2: Safety and efficacy of pembrolizumab (pembro) plus 5fluorouracil (5-FU) and cisplatin for first-line (1L) treatment of advanced gastric cancer. J Clin Oncol 35: 4012-4012, 2017.

108 Tabernero J, Bang YJ, Fuchs CS, Ohtsu A, Kher U, Lam B, Koshiji M and Van Cutsem E: KEYNOTE-062: Phase III study of pembrolizumab (MK-3475) alone or in combination with chemotherapy versus chemotherapy alone as first-line therapy for advanced gastric or gastroesophageal junction (GEJ) adenocarcinoma. J Clin Oncol 34: no. 4 supp, 2016. doi: 10.1200/jco.2016.34.4_suppl.tps185. [Epub ahead of print]

109 Kang YK, Boku N, Satoh T, Ryu MH, Chao Y, Kato K, Chung HC, Chen JS, Muro K and Kang WK: Nivolumab in patients with advanced gastric or gastro-oesophageal junction cancer refractory to, or intolerant of, at least two previous chemotherapy regimens (ONO-4538-12, ATTRACTION-2): a randomised, double-blind, placebo-controlled, phase 3 trial. The Lancet 390: 2461-2471, 2017.

110 Hofmann M, Stoss O, Shi D, Büttner R, Van De Vijver M, Kim W, Ochiai A, Rüschoff J and Henkel T: Assessment of a HER2 scoring system for gastric cancer: results from a validation study. Histopathology 52: 797-805, 2008.

111 Bang YJ, Van Cutsem E, Feyereislova A, Chung HC, Shen L, Sawaki A, Lordick F, Ohtsu A, Omuro Y and Satoh T: Trastuzumab in combination with chemotherapy versus chemotherapy alone for treatment of HER2-positive advanced gastric or gastro-oesophageal junction cancer (ToGA): a phase 3, open-label, randomised controlled trial. The Lancet 376: 687697, 2010.

112 Zaanan A, Palle J, Soularue E, Leroy F, Louafi S, Tougeron D, Manfredi S, Artru P, Pozet A and Taieb J: Trastuzumab in Combination with FOLFIRI in Patients with Advanced HER2-Positive Gastro-Esophageal Adenocarcinoma: A Retrospective Multicenter AGEO Study. Target Oncol 13: 16, 2017.

113 Wang KL, Wu T, Choi IS, Wang H, Resetkova E, Correa AM, Hofstetter WL, Swisher SG, Ajani JA and Rashid A: Expression of epidermal growth factor receptor in esophageal and esophagogastric junction adenocarcinomas. Cancer 109: 658667, 2007.

114 Lordick F, Kang YK, Chung HC, Salman P, Oh SC, Bodoky G, Kurteva G, Volovat C, Moiseyenko VM and Gorbunova V: Capecitabine and cisplatin with or without cetuximab for patients with previously untreated advanced gastric cancer (EXPAND): a randomised, open-label phase 3 trial. Lancet Oncol 14: 490-499, 2013
115 Wilke H, Muro K, Van Cutsem E, Oh SC, Bodoky G, Shimada Y, Hironaka S, Sugimoto N, Lipatov O and Kim TY: Ramucirumab plus paclitaxel versus placebo plus paclitaxel in patients with previously treated advanced gastric or gastro-oesophageal junction adenocarcinoma (RAINBOW): a double-blind, randomised phase 3 trial. Lancet Oncol 15: 1224-1235, 2014.

116 Li J, Qin S, Xu J, Xiong J, Wu C, Bai Y, Liu W, Tong J, Liu Y and Xu R: Randomized, double-blind, placebo-controlled phase III trial of apatinib in patients with chemotherapy-refractory advanced or metastatic adenocarcinoma of the stomach or gastroesophageal junction. J Clin Oncol 34: 1448-1454, 2016.

117 Fuchs CS, Tabernero J, Al-Batran SE, Chau I, Ilson DH, Van Cutsem E, Ferry D, Emig M, Melemed AS and Vanvoorden V: A randomized, double-blind, placebo-controlled phase III study of cisplatin plus a fluoropyrimidine with or without ramucirumab as first-line therapy in patients with metastatic gastric or gastroesophogeal junction (GEJ) adenocarcinoma (RAINFALL, NCT02314117). J Clin Oncol 33: 4131-4131, 2015.

118 Li G, Zhao S, Zhang X, Wang W, Liu J, Xue K, Li X, Guo Y and Wang L: Comparison of the proliferation, cytotoxic activity and cytokine secretion function of cascade primed immune cells and cytokine-induced killer cells in vitro. Mol Med Rep 12: 2629-2635, 2015.

119 Gao D, Li C, Xie X, Zhao P, Wei X, Sun W, Liu HC, Alexandrou AT, Jones J and Zhao R: Autologous tumor lysatepulsed dendritic cell immunotherapy with cytokine-induced killer cells improves survival in gastric and colorectal cancer patients. PloS One 9: e93886, 2014.

120 Fan Y, Zhao H, Yu J, Li H, Ren B, Cao S, Liu L, Li R, Zhang N and An X: Clinical efficacy of chemotherapy combined with cytokine-induced killer cell treatment after curative resection for gastric cancer patients. Chin J Cancer Biotherapy 2: 016, 2012.

121 Chen Y, Guo ZQ and Shi CM: Efficacy of adjuvant chemotherapy combined with immunotherapy with cytokineinduced killer cells for gastric cancer after d2 gastrectomy. Int J Clin Exp Med 8: 7728-7736, 2015.

$122 \mathrm{Mu}$ Y, Zhou CH, Chen SF, Ding J, Zhang YX, Yang YP and Wang WH: Effectiveness and safety of chemotherapy combined with cytokine-induced killer cell/dendritic cell-cytokine-induced killer cell therapy for treatment of gastric cancer in China: A systematic review and meta-analysis. Cytotherapy 18: 1162-1177, 2016.

123 Ishikawa H, Imano M, Shiraishi O, Yasuda A, Peng YF, Shinkai M, Yasuda T, Imamoto H and Shiozaki H: Phase I clinical trial of vaccination with LY6K-derived peptide in patients with advanced gastric cancer. Gastric Cancer 17: 173-180, 2014.

124 Higashihara Y, Kato J, Nagahara A, Izumi K, Konishi M, Kodani T, Serizawa N, Osada T and Watanabe S: Phase I clinical trial of peptide vaccination with URLC10 and VEGFR1 epitope peptides in patients with advanced gastric cancer. Int $\mathrm{J}$ Oncol 44: 662-668, 2014.

125 Mazzaferro V, Coppa J, Carrabba MG, Rivoltini L, Schiavo M, Regalia E, Mariani L, Camerini T, Marchianò A and Andreola $\mathrm{S}$ : Vaccination with autologous tumor-derived heat-shock protein gp96 after liver resection for metastatic colorectal cancer. Clin Cancer Res 9: 3235-3245, 2003.

126 Jonasch E, Wood C, Tamboli P, Pagliaro L, Tu S, Kim J, Srivastava $\mathrm{P}$, Perez C, Isakov L and Tannir N: Vaccination of metastatic renal cell carcinoma patients with autologous tumour-derived vitespen vaccine: clinical findings. Br J Cancer 98: 1336-1341, 2008. 
127 Zhang K, Peng Z, Huang X, Qiao Z, Wang X, Wang N, Xi H, Cui J, Gao $Y$ and Huang $X$ : Phase II trial of adjuvant immunotherapy with autologous tumor-derived Gp96 vaccination in patients with gastric cancer. J Cancer 8: 1826-1832, 2017.

128 Ajani JA, Randolph Hecht J, Ho L, Baker J, Oortgiesen M, Eduljee A and Michaeli D: An open-label, multinational, multicenter study of G17DT vaccination combined with cisplatin and 5-fluorouracil in patients with untreated, advanced gastric or gastroesophageal cancer: The GC4 study. Cancer 106: 1908-1916, 2006.

129 Watson SA, Michaeli D, Grimes S, Morris TM, Crosbee D, Wilkinson M, Robinson G, Robertson JF, Steele RJ and Hardcastle JD: Anti-gastrin antibodies raised by gastrimmune inhibit growth of the human colorectal tumour AP5. Int $\mathrm{J}$ Cancer 61: 233-240, 1995.
130 Masuzawa T, Fujiwara Y, Okada K, Nakamura A, Takiguchi S, Nakajima K, Miyata H, Yamasaki M, Kurokawa Y and Osawa R: Phase I/II study of S-1 plus cisplatin combined with peptide vaccines for human vascular endothelial growth factor receptor 1 and 2 in patients with advanced gastric cancer. Int J Oncol 41: 1297-1304, 2012.

Received March 27, 2018

Revised April 18, 2018

Accepted April 19, 2018 